\title{
Vibration stability of Orion laser facility
}

\section{James MW Brownjohn BSc PhD DEng CEng FIStructE FIMechE}

Professor, College of Engineering, Mathematics and Physical Sciences, University of Exeter, UK; Full Scale dynamics Ltd, Sheffield, UK

\section{Giovanna Zanardo PhD CEng MICE MIAustE CPEng}

Main Roads, Perth, Western Australia

\section{David G Brown BSc MBA MAPM CEng FIMechE}

Senior Engineering Manager, Atomic Weapons Establishment, Aldermaston, UK

\section{Sarah Prichard BA BAI MA PhD CEng MICE MIStructE}

Associate Director, BuroHappold Engineering, Bath, UK

Contact author: $\quad$ Professor James Brownjohn

Vibration Engineering Section

College of Engineering. Mathematics and Physical Sciences

University of Exeter

Harrison Building

Exeter EX4 4QF

E-mail: j.brownjohn@exeter.ac.uk

Tel: +44 1392723698

Body text word count: 5452

Number of figures:

Number of tables:

Keywords: dynamics, geotechnical engineering, nuclear power, field testing and monitoring 


\begin{abstract}
In 2005 the UK Ministry of Defence awarded a contract for construction of the Orion laser facility at the Atomic Weapons Establishment (AWE). Orion delivers a power density of $10^{21} \mathrm{~W} / \mathrm{cm}^{2}$ on a $5 \mu \mathrm{m}$ target, making it a world class facility for the study of high energy density physics.

The ability to target to such high precision depends on 'stability' of the building and internal structures with respect to thermal expansion and vibrations.

This paper concerns experimental activities supporting prediction and evaluation of the minute vibrations against a 'budget' comprising effects of all vibration sources, internal and external, and the sequence of experimental campaigns and signal evaluation that fed into this process.

This involved a sequence of dynamics-based measurements of:

- foundation pile stiffness

- vibration propagation from both controlled and uncontrolled sources at stages during the construction and finally

- evaluation of vibration levels in the as-built facility due to internal machinery and the few external vibration sources passing through the sophisticated vibration barrier.
\end{abstract}

The approach focused on time series of vibrations in the design phase, and on evaluation of statistical properties of displacement power spectral density functions. 


\section{Introduction: Capability and requirements for Orion}

In 2005 the UK Ministry of Defence awarded a contract for construction of the Orion high-power laser facility at the Atomics Weapons Establishment (AWE)(Edwards, 2006). Orion was designed to support research on the performance of ageing warheads in the UK's nuclear stockpile under restrictions of the Comprehensive (nuclear) Test Ban Treaty by enabling experimental measurements of the physical properties of materials in extreme regimes of temperature and density that occur in an operating warhead. Such measurements will help to bridge between interpretive and predictive computer codes by providing experimental data for benchmarking. Construction activities began in 2005, commissioning tests continued through to 2013 with the first experimental results (Hoarty et al., 2013).

The Orion facility comprises 10 'long pulse' lasers that will deliver up to $5 \mathrm{~kJ}$ at $351 \mathrm{~nm}$ (ultraviolet) in ten 1 nanosecond duration shapeable pulses of $500 \mathrm{~J}$, and two 'short pulse' beams that will deliver $500 \mathrm{~J}$ at $1053 \mathrm{~nm}$ (infrared) in 0.5 picosecond pulses (Oades et al., 2004). The long pulse lasers can be used to compress the target material, and the short pulse lasers to heat it to many millions of degrees centigrade enabling the behaviour of matter at extreme densities and temperatures to be studied. Orion delivers $10^{21} \mathrm{Wcm}^{-2}$ to target making it a world-class facility for research into high energy density physics.

Orion's capability is also valuable for research on plasma physics e.g. to study conditions on stars and super-dense matter, as well as particle acceleration, isotope production and advanced energy production (fusion) schemes. Hence $15 \%$ of Orion's time is made available to the academic community.

\section{Orion components}

The laser (Figure 1) is housed in a purpose-built structure having a $97 \mathrm{~m}$ by $57 \mathrm{~m}$ footprint. The building ground floor houses plant rooms and offices, while the long and short-pulse laser beam lines are supported on steel frames bolted directly to the concrete slab in the first floor laser hall. These frames were designed to have natural frequencies exceeding $20 \mathrm{~Hz}$ for undisclosed reasons. Short pulse laser beams pass through optical compression stages (also on first floor) and both long and short pulse beams are directed at the target that is fixed to the ground floor in a multi-storey target hall with $1.5 \mathrm{~m}$ thick concrete walls. The ground floor is a $0.6 \mathrm{~m} \mathrm{RC}$ slab with $0.6 \mathrm{~m}$ edging supported by a grillage of $0.9 \mathrm{~m}$ piles at $5.4 \mathrm{~m}$ centres while the first floor, supported on $0.6 \mathrm{~m}$ square columns is a waffle slab with $0.9 \mathrm{~m}$ sub-grid spacing. The building envelope is a separate structure supported on double-sleeved piles, which isolate the foundations of the vibration sensitive elements from wind buffeting of the envelope. Although final pile details are unknown, $0.9 \mathrm{~m}$ test piles were $22.5 \mathrm{~m}$ depth, passing through layers of Silchester Gravel, Bagshot Formation, a transition zone, with London Clay formation for the lower half of the pile.

In order to function correctly, the Orion laser system must control the propagation of the laser beam over a path length of hundreds of metres with multiple reflections with targeting accuracy of $25 \mu \mathrm{m}$ for the long pulse lasers and $5 \mu \mathrm{m}$ for the short pulse lasers. The alignment of the laser lines over the long term is not a concern due to realignment before each firing sequence, but positional stability is required during the alignment and firing sequence that is expected to last one hour. This led to development of a 'stability budget' to be applied in the design of the structural and the optical support structure (Swensen et al., 1997). The two sources of instability were considered to be dynamic 
-due to vibrations, and static -due to thermal effects and ground settlement and creep. This latter movement, which is normally important in structural design, is truly 'long term' and is compensated for in the laser realignment. This paper considers the harder to deal with dynamic component due to ground borne vibration and dynamic wind pressure, for which $2.5 \mu \mathrm{m}$ was available to the facility designers, BuroHappold. This $2.5 \mu \mathrm{m}$ is the stability budget which could not be exceeded by the sum total of all dynamic displacements during the firing sequence.

For ground borne vibrations the main source was considered to be vehicles moving around the facility and along the A340 road that runs along the perimeter close to the Orion site (Figure 2). Effects of infrequent discrete events such as hydrodynamic testing would not be considered. For wind, direct forces on the building envelope were considered along with the effect of vibration transmitted from nearby structures buffeted by wind, including trees.

\section{Outline procedure and timeline for design and assessment of vibration stability}

The procedure began with an evaluation of the vibration environment on the site by an independent contractor in 2005, providing the statistical frequency domain characteristics of the site vibrations. The measurements also provided two scalable design signals representative of both frequency content and direction of the vibrations propagating through the site.

As the building foundation is a major component in the vibration transmission path and the one that could be optimized for best stability performance, a number of foundation types were considered and evaluated using shaker testing and ambient vibration measurements.

The two design signals were adapted to represent propagating vibration waves providing direct displacement input at locations for groups of piles in the detailed finite element (FE) model created to represent the foundation, superstructure and laser support frames. Inputs were applied through a pilesoil interface model whose characteristics were determined from the pile shaker tests. The simulations did not account for mitigating effect of the structure, a strategy with acceptable conservatism proved by sample vibration measurements during the construction sequence.

The FE model was used in an exhaustive sensitivity analysis by trying all combinations of sensible design parameters of piles and superstructure. Rotations and displacements of components of the laser optical system were combined in a square root sum of squares sense for comparison with the stability budget.

The work culminated in a design that met the stability specification, and foundation construction began in April 2006. Vibration measurements were made of the foundation and partially complete ground floor slab in November 2006, then of the complete ground and first floor slabs in 2007 under similar controlled conditions. It was found that there was generally a ratio of 2-2.5 reduction in measured vibrations due to the presence of the structure.

In June 2009 vibration measurements were again made of the competed structure, this time including effects of internal machinery (compressors, environmental control), confirming the stability of the structure due to external and internal vibration sources. A parallel desk study of dynamic (buffeting) wind forces on the building envelope demonstrated that for the final envelope design, wind was a lesser concern and through statistical combination with structural vibrations would not compromise stability.

Due to the nature of the site and the constraints of the commercial arrangements, the study could not be perfectly controlled e.g. with exact same measurement points under exact same conditions from 
2005 to 2009 and there were no opportunities to repeat or extend measurements that might be available within a controlled research experiment.

Nevertheless, there is sufficient linkage, intended by the overseeing authority (AWE), to demonstrate a logical sequence leading to a proof that the building satisfies the original stability requirements. The final proof has been in the extended commissioning that demonstrated no adverse effect of vibration instability and in early experimental results (Hoarty et al., 2013).

\section{Brownfield Site vibration survey}

AWE was built on the site of the World War II Aldermaston Airfield, whose runway ran diagonally across the present site of the Orion building. The runway was still in place at the vacant Orion site when preliminary vibration measurements were made in 2003 , followed by a more comprehensive survey in 2005 whose main aim was to establish the levels of ambient vibration associated with activities adjacent to the site, such as vehicles moving on internal roads and public highways outside the perimeter. A total of 14 days of measurements had already been conducted by a third party contractor over a three-week period using a combination of Willmore Mk IIIA seismometers supplemented by the Ranger and Geospace units and sampled at $250 \mathrm{~Hz}$. This sample rate (or $200 \mathrm{~Hz}$ or $256 \mathrm{~Hz}$ ) is typical of seismometers, although in fact displacement levels were of little consequence above $35 \mathrm{~Hz}$.

The majority of the 2005 measurements (White, 2005) were of ambient vibration at groups of measurements points selected from a grid of locations covering the site to indicate any likely sources, the degree of commonality and its spatial extent. The duration of measurements also allowed for estimation of the $95 \%$ ile vibration (displacement) levels reaching the structure footprint.

The measurements points (or test points, TP) are indicated as TP1-9 in a regular grid in Figure 2 and marked with a small symbol. The focus of measurements was also on three types of test foundations installed within the footprint of the Orion structure: $0.6 \mathrm{~m}$ and $0.9 \mathrm{~m}$ diameter bore piles and 3 metre square pads. Hence all measurements recorded vertical and horizontal velocities at A2, $\mathrm{C} 2$ (test foundations) and at TP4 (TP indicates a ground spike), with the majority of measurements also recording at C3, B1, C1 (all test foundations), TP7 and either TP8 or B2. Only a few measurements were made of remaining ground spikes so the picture of propagation across the site was limited.

The foundation response was also evaluated by forced vibration testing.

\section{Vibration stability simulation approach and design signal selection}

Several options were explored for simulating the effect of ground borne vibration on the Orion structure based on the vibration survey data. ANSYS software had been selected for the structural vibration study, and one major factor on the approach was the transparency of the methodology.

While ANSYS offers options for working in the frequency domain, which is an approach well suited to random vibration analysis requiring statistical properties of response, this is not well adapted for differential support excitation over the length of the structure and is also difficult for non-specialists to interpret. Due to the many organisations involved in the multiple review stages in the design process a clear and simple presentation format was an essential component, so time domain analysis was chosen using carefully selected and optimally representative vibration signals.

\subsection{Selection of 'design signals'}


Due to the computational effort associated with time domain analysis, only two time series (signals) were sought from the large dataset of vibration recordings, but these would need to be representative of the site vibration character. Characteristics being sought for these two 'design' signals were that they should

1) be clear above background noise,

2) have relatively short duration (around 10 seconds to limit simulation costs),

3) have spectral content consistent with that observed during three weeks of measurements,

4) show similar features in time and frequency between different measurement points indicating a common origin and

5) not include features such as mechanical (real) or electrical (instrumentation) transients from within the site (figure 2) since these would be prevented during Orion laser firing.

The time series were derived from continuous measurements over the 14 separate working days including periods of construction activity and at night, but mainly during working hours. It was found that the most effective technique to check for the above criteria simultaneously was to scroll through sequential (262-second) spectrograms using bespoke MATLAB scripts. Spectrograms were found to represent the signals with sufficient detail in both time and frequency to identify candidates for further investigation of time series features and frequency domain relationships.

For the same data, statistical analysis was carried out by subdividing velocity time series into 4second frames, converting to frequency domain (by discrete Fourier transform or FFT), converting to displacement through division by circular frequency, then assembling FFT blocks into large threedimensional arrays (record no. vs. frequency vs. displacement amplitude) for each recording session, typically of one day or one night. Anomalies (mechanical or electrical overload) were automatically excluded. The sample size allowed for reliable evaluation of statistical distribution at $0.25 \mathrm{~Hz}$ frequency spacing and evaluation of mean, median and $95 \%$ ile values of displacement power spectral densities (PSDs) for each frequency bin as well as root mean square (RMS) over given frequency ranges, chosen as either $1 \mathrm{~Hz}-35 \mathrm{~Hz}$ or $2 \mathrm{~Hz}-35 \mathrm{~Hz}$.

Figure 3 shows $95 \%$ ile displacement PSD vertical velocity spectrogram from test point locations during a day with minimal construction activity i.e. representative of operational conditions for the laser with ground-borne vibrations from local traffic and normal activities within AWE. Figure 3 also shows the TP7 signal as a spectrogram indicating the variation of signal strength with time. The main observation here is that there are no exceptional events and that energy concentrates around $5 \mathrm{~Hz}$.

Extensive study of the data and discussions on the appropriate representative signals resulted in two example signals appearing to propagate from opposite ends of the site and also having different frequency content were selected and labelled 'signal_02' and 'signal_89'. The original time series for signal_02 recorded on $0.6 \mathrm{~m}$ diameter test piles either side of the runway are presented in Figure 4.

\subsection{Signal generation and simulation}

From the two signals, short periods ( 8 and 12 seconds) were extracted and scaled to have RMS displacements matching the $95 \%$ values for the site determined by aggregating all the measurements.

The marching method developed by (Hao, Oliveira, \& Penzien, 1989) was used to generate time series for centre points of 12 groups of piles over the building footprint. The procedure generates a common ground motion propagating from a specific location, allowing for attenuation, dispersion and delay. The analysis procedure makes use of frequency domain relationships (specifically coherence) between opposite ends of the site, determined from the full record from which the few seconds of time series were finally generated, those few seconds representing relatively strong parts of the 256-second signal showing commonality throughout the site. Consistent with the original signals, the derived inputs were taken to derive a signal propagating with spherical wave fronts from points on opposite 
corners of the site. Sample intervals of 0.004 second were retained from the original signals, and the set of 12 horizontal and vertical signals for signal_02 are shown in Figure 5.

\subsection{Foundation performance studies and finite element simulations}

The Orion super-structure was straightforward to model due to the known properties and dimensions of the concrete, whereas the properties of the foundation required experimental studies using forced vibration, such as with electro-dynamic shakers (Figure 6). Pile stiffnesses in each direction were estimated from reliable data at the lowest possible frequency points on the receptance frequency response functions (FRFs). In theory receptance FRFs should be asymptotic to static stiffness at $0 \mathrm{~Hz}$ (DC) values but for low frequencies with the shaker force dropping quickly due to the frequency squared force characteristic, values were chosen where H1 and H2 FRF estimators began to diverge. The $\mathrm{H} 1$ estimator is used where input (force) signal is contaminated by noise and $\mathrm{H} 2$ where the output (response) is contaminated (Randall, 1987). The values were cross-checked by time series curvefitting, giving stiffness values of $1 \mathrm{GN} / \mathrm{m}$ and $0.1 \mathrm{GN} / \mathrm{m}$ for $0.6 \mathrm{~m}$ pile in vertical and horizontal directions, and $0.2 \mathrm{GN} / \mathrm{m}$ and $0.02 \mathrm{GN} / \mathrm{m}$ for $0.6 \mathrm{~m}$ pile in vertical and horizontal directions. For pads, values were $0.2 \mathrm{GN} / \mathrm{m}$ and $1 \mathrm{GN} / \mathrm{m}$ (i.e. stiffer horizontally).

In practice it has been found (Dobry \& Gazetas, 1988) that pile stiffness is reduced in the presence of nearby piles so reductions factors $1 /(1+\alpha)$ are used, with $0.2<\alpha<0.3$ for Orion, where $\alpha$ is the dynamic interaction factor for oscillating piles.

Using the experimental values, modal analysis of the structure and foundation system determined that the fundamental mode frequencies were $3 \mathrm{~Hz}$ using $0.6 \mathrm{~m}$ piles, $4.9 \mathrm{~Hz}$ for $0.9 \mathrm{~m}$ pile and $7 \mathrm{~Hz}$ for pad foundations. Given that energy content of ground displacement spectrum was concentrated in the range $2-4.5 \mathrm{~Hz}, 0.6 \mathrm{~m}$ piles were not viable. While pad foundations produced higher frequency modes, in the free vibration measurements they consistently showed the highest vibration levels in the ambient vibration measurements and they also picked up higher vibration levels than piles when foundations on the opposite side of the runway were driven by shakers. Hence the $0.9 \mathrm{~m}$ pile was chosen and foundation construction could begin.

Performance simulations were carried out on the structure using pile group inputs generated from signal_02 and signal_89. Alongside the delayed and attenuated versions, analyses were carried out using common signals i.e. the two signals applied uniformly to each pile. After much discussion it was reasoned that because the free vibration signals had been measured at the tops of the sample piles, they already represented the behavior of the piles, hence the signals were applied as imposed translations to the pile/structure interfaces. While imperfect, the approach is one used elsewhere in simulations of effect of traffic-induced vibrations (Hao et al., 2001) and the method was expected to generate conservative predictions of translation; with the outputs from multiple ANSYS simulations the design of the superstructure converged to a system that allowed beam line precision within 2.13 $\mu \mathrm{m}$.

\subsection{Wind and vibration load case combination}

Wind gusts were also a concern due to the varying pressures and resulting deformations possible in the one-hour alignment period. Eight years of wind data from the site anemometer were used to determine the range of wind speeds, and were compared with data from Boscombe Down. Pressure changes over the one-hour period were calculated and the $95 \%$ ile value adopted for design.

In the initial design the envelope was partially supported on the massive target hall walls, which were separated by a movement joint from the target hall floor. This design resulted in unacceptable displacement of the laser hall so the design was modified to decouple the envelope steelwork from the target hall walls. 
Instead the envelope is supported on double-sleeved piles transferring the load deep into the ground. As vibrations experienced by Orion are primarily surface waves, the design should largely isolate the laser component support structure and target structure from wind effects. Optical modeling of the remaining effect of wind load alone showed beam accuracy to be within $0.84 \mu \mathrm{m}$ for $95 \%$ ile wind range.

To combine wind and ground borne vibration effects to get a $95 \%$ ile value, $78 \%$ ile values of each of the wind and ground borne vibration effects were combined (since $5 \%$ of the time $78 \%$ ile values of both of each would be exceeded). The result is $1.84 \mu \mathrm{m}$ for the combination of load cases, hence ground borne vibration alone governs dynamic stability.

\section{Ground borne vibration studies during construction}

The vibration environment on the Orion structure was assessed twice during the construction phase, first in November 2006 when the majority of bore piles had been installed and part of the ground slab was in place and second in June 2007 when both the ground slab and the first floor laser hall structures were structurally complete.

For the 2006 measurements, an array of 15 Force balance accelerometers (FBAs) was deployed. Figure 7 shows the partial slab existing at the time of the measurements and arrangement of measurement points. Points marked 1-5 along a diagonal, also points 6 and 7 indicate locations on the slab where accelerometers were mounted directly on concrete surface of the slab and designated stp17, while points 1-4 on the corners indicate locations where accelerometers were attached to steel spikes driven into the soil and designated spk1-4. The $\mathrm{x}$-axis and $\mathrm{y}$-axis respectively correspond to gridlines $4-7$ and B-G in Figure 2, with stp6 $\approx \mathrm{TP} 3$ and $\operatorname{stp} 1 \approx \mathrm{TP} 2$.

A single Guralp CMG3-ESPD triaxial seismometer was used in parallel with one of the sensors at stp6 to corroborate the information from the accelerometer. The Guralp has a noise floor at least an order of magnitude below the FBAs.

For the 2007 measurements, 20 FBAs were arranged on the slab and partially completed upper level (laser and compressor halls) indicated in Figure 2 as LS1, GS1, LS3, GS3, GS4 and TH1 as well as on ground spikes E1, E2. GS are (ground floor) slab test points, LS are upper level (first floor) test points and $\mathrm{TH}$ is target hall.

For both measurements six accelerometers were arranged in tri-axial sets and not moved for all of the one-hour recordings (six for 2006 and five for 2007) while other accelerometers were rotated to vertical, and (two) horizontal directions. Recordings were made with construction activities shut down to represent typical conditions for operating the laser.

In addition, for both 2006 and 2007 slab measurements, ground vibration pulses were deliberately generated using a heavy vehicle (fire engine) driving over speed bumps (Figure 7). Simulations of the vehicle, its suspension and the bump profile (Al Dimashki, 2011) provided an estimate of $\pm 60 \mathrm{kN}$ for the reaction pulse for each axle and of the measured response in the alignment spk1 to spk4 which are at opposite corners of the slab as indicated in Figure 8. Stp1 to stp5 are the points equally spaced along the spk 1 to spk 4 interval. In each example there are two transients as the two axles pass over the bump with vehicle speed of approximately 5 miles per hour.

GS1 (2007) corresponds to stp3 (2006), while GS3 (2007) is at the far end of the structure from GS1. There is no obvious difference in the nature of the response of the structure between the two measurements, although both clearly demonstrate the delay and attenuation of the travelling vibration waves. 
Corresponding to the measurements presented in Figure 3 for the brownfield site in 2005, Figure 9 shows corresponding levels for the 2006 and 2007 measurements, also as average values of displacement. The PSD for the 2006 measurement with the partial ground floor slab show a clear reduction of (vertical) response and no obvious resonance in the $5 \mathrm{~Hz}$ region. For the 2007 measurement with complete ground floor and first floor slabs a clear resonance at $5 \mathrm{~Hz}$ has reappeared in all signals suggesting a rigid body vibration of the whole building. The first floor slab exhibits apparent resonance above $30 \mathrm{~Hz}$, but the displacement levels are so small as to be of no concern.

More detailed analysis of the signals from the three stages show that vibration levels have reduced overall by $2-2.5 \mu \mathrm{m}$ (in terms of the $95 \%$ ile displacement levels).

\section{Evaluation of percentile levels and performance of instrumentation}

For the ambient vibration measurements in 2005, 2006 and 2007 the principal metric of ground and structural vibration levels was the $95 \%$ ile of displacement response. Determining this value from measurements is complicated by choice of appropriate recording conditions, instrumentation performance and selection of appropriate bandwidth.

The $95 \%$ ile criterion avoids the effect of extreme and unrepresentative transients in the analysed signals that can skew average values, provided the extended measurement, which lasts one or more hours, does not contain continued unusually strong signals such as from temporary construction machinery.

Instrumentation performance is crucial. Accelerometers typically used for low-vibration measurements have a capacitive coupling to disconnect the power signal from the signal, resulting in poor performance and noise levels rising asymptotically towards DC $(0 \mathrm{~Hz})$. The FBA is a true DC accelerometer but has its own background noise levels, quoted by the manufacturer as 'resolution' of $1 \mu \mathrm{g}$ or $9.8 \mu \mathrm{m} / \mathrm{sec}^{2}$. Tests by the first author in the quiet environment of the Diamond Light Source at night (Brownjohn, 2007) have shown that with high quality acquisition equipment background levels for the FBA can be as low as $1\left(\mu \mathrm{m} / \mathrm{sec}^{2}\right)^{2} / \mathrm{Hz}$, which sums to $1 \mu \mathrm{g}$ over $100 \mathrm{~Hz}$ bandwidth. The Guralp CMG-3ESP has superior performance, with noise levels below the US Geological Survey New Low Noise Model (Ringler \& Hutt, 2010). The Willmore seismometer is reported as having selfnoise of $10^{-4} \mu \mathrm{m} / \mathrm{s}^{2} / \sqrt{\mathrm{Hz}}$.

Figure 10 compares the FBA and the Guralp for vertical response of the partial ground floor slab (2006 measurements). Subsequent measurements of extreme low-vibration facilities have shown that the capacitor-coupled accelerometers have unacceptable performance for this type of measurement. The PSD plots show clearly that the Guralp performs better across the whole frequency range, but the critical part of the response between $2 \mathrm{~Hz}$ and $20 \mathrm{~Hz}$ is well represented in the $95 \%$ ile curves. The plots also show that mean values enhance resonances due to short-lived transients.

The cumulative distribution functions (CDFs) show the effect of the lower limit of the range for calculating broadband RMS. When including only contributions above $4 \mathrm{~Hz}$ there is little difference between results for the two sensors but when including components above $2 \mathrm{~Hz}$ the FBA overestimates levels by approximately one-third due to the higher levels of low frequency noise.

\section{As built structure performance with plant operation}

In the last phase of measurements in June 2009 separate from the design process, and commissioned by the operator (AWE), vibration levels on the floors of the laser, compressor and target halls were checked to show that vibrations generated by rotating machinery and piping did not cause the 
stability limit to be exceeded. Machinery included a range of air compressors, water pumps and air handling units located on the plant room floor below the compressor hall. These machines have rotational speeds around 1450 or 2850 revolutions per minute, so if detected would generate sharp peaks in vibration response just below $25 \mathrm{~Hz}$ and $50 \mathrm{~Hz}$.

Measurement locations were the same as for the 2007 measurements (in laser, compressor and target halls) to permit comparison. Figure 11 shows measurement in the three comparative locations, along with one of the additional measurements at a chilled water pump in the plant room. The view of the compressor hall measurement shows that accelerometers were arranged in groups of four, allowing measurement in two translational directions. By differencing signals and using a baseline of $1 \mathrm{~m}$, rotations about two axes could be obtained. The remaining two degrees of freedom would be obtained by rotating the accelerometer arrangement $90^{\circ}$ about the vertical axis.

$95 \%$ ile PSDs for measurements in the laser and target halls are shown in Figure 12. Compared to the 2007 measurements (Figure 9) the values in the laser hall are significantly reduced in the higher frequency range, as if the apparent amplification effect of the first floor slab has completely disappeared, other than weak spectral peaks around $17 \mathrm{~Hz}$. The machinery effect is clear in the peak at $24 \mathrm{~Hz}$ but the displacement levels are trivial, with rotations at the noise floor, and the overall conclusion is that displacements are well within the stability budget for any combination of plant machinery operation.

\section{Summary and conclusions}

A series of measurements and data analyses spanning five years was aimed at ensuring that vibration levels at components of the Orion laser facility would be within displacement stability budgets, ensuring that beam line precision of $5 \mu \mathrm{m}$ could be achieved at the $95 \%$ ile level of vibrations during the one-hour pre-firing alignment procedure.

Time domain analysis was chosen for transparency and because it lent itself to multiple-support excitation. While selection of foundation type was guided by site vibrations measurements on the piles due to ambient and artificial excitation, simulations were carried with direct drive of pilecaps.

Simulations showed vibrations to be acceptable and measurements of the structure at three stages during construction confirmed this to be the case. Finally, measurements on the as-built during worstcase conditions of machinery operation showed that machinery contribution to stability is negligible.

Despite vibrations levels being close to noise levels for high-grade force balance accelerometers, the measurements were clear enough to demonstrate the mitigating effects of the structure on the vibration levels, the small resonance of the first floor slab and ultimately the damping of the optical system support frames and other components on the vibration levels.

There were limitations on the range of vibration measurements due to operational and security conditions but it is clear that the unusual foundation design and attention to optimisation of the structure design even while the foundation system was being installed allowed for good performance to be achieved.

\section{Acknowledgements}

(c) British Crown Owned Copyright 2014/AWE 
Published with permission of the Controller of Her Britannic Majesty's Stationery Office.

"This document is of United Kingdom origin and contains proprietary information which is the property of the Secretary of State for Defence. It is furnished in confidence and may not be copied, used or disclosed in whole or in part without prior written consent of Defence Intellectual Property Rights DGDCDIPR-PL - Ministry of Defence, Abbey Wood, Bristol, BS34 8JH, England."

The authors acknowledge the assistance of Prof. Paul Reynolds and Dr Christopher Middleton.

\section{Figures}

Figure 1: Orion schematic.

Figure 2: Orion site

Figure 3: Vibration environment on $22^{\text {nd }}$ September 2005 for brownfield site.

Left: $95 \%$ ile PSD, right velocity spectrogram (reference $1 \mathrm{~mm} / \mathrm{sec}$ )

Figure 4: Signal_02 original time series

Figure 5: Set of generated input signals.

Figure 6: Shaker pile tests

Figure 7: Fire engine and 'fire bump' location

Figure 8: Fire bump time histories. Left for 2006 slab-only measurements and right for 2007 slab+partial structure measurements.

Figure 9: PSDs of vertical vibration with construction of 2006 and 2007 measurements. stp3 (2006) compares with GS1 (ground floor slab) and LS1 (first floor slab) in 2007.

Figure 10: Comparison of Ground floor slab response using FBA and Guralp CMG-3ESP.

Figure 11: Optical and mechanical machinery. From top left, clockwise: target chamber, chilled water pump in plant room, short/long pulse laser frames, optical compressor.

Figure 12: Displacement PSDs in laser hall and target hall from 2009 measurements. 


\section{References}

Al Dimashki, M. M. (2011). Effects of ground vibrations on the performance of foundation structures. PhD Thesis, Department of Civil and Structural Engineering, University of Sheffield.

Brownjohn, J. M. W. (2007). Noise characteristics of sensors for extreme low level vibration measurements. In Proceedings of the 25th International Modal Analysis Conference (IMAC $X X V): 1-8$. Orlando, FL, USA

Dobry, R., \& Gazetas, G. (1988). Simple method for dynamic stiffness and damping of floating pile groups. Géotechnique, 38(4): 557-574. doi:10.1680/geot.1988.38.4.557

Edwards, C. (2006). Project Orion : Journey to the hottest most dense place on earth. Defence Management Journal 34: 86-88.

Hao, H., Oliveira, C. S., \& Penzien, J. (1989). Multiple-station ground motion processing and simulation based on smart-1 array data. Nuclear Engineering and Design, 111(3): 293-310. doi:10.1016/0029-5493(89)90241-0

Hao, H., Ang, T. C., Shen J., (2001). Building vibration to traffic-induced ground motion. Building and Environment 36: 321-336 doi:10.1016/S0360-1323(00)00010-X

Hoarty, D. J., Allan, P., James, S. F. et al., (2013). The first data from the Orion laser; measurements of the spectrum of hot, dense aluminium. High Energy Density Physics, 9(4): 661-671. doi:10.1016/j.hedp.2013.06.005

Oades, K., Evans, A., Slark, G., et al. . (2004). Target diagnostics for the future AWE Orion laser facility. Review of Scientific Instruments, 75(10): 4222. doi:10.1063/1.1787605

Randall, R. B. (1987). Frequency Analysis. Naerum, Denmark: Bruel \& Kjaer.ISBN 8787355078

Ringler, A. T., \& Hutt, C. R. (2010). Self-noise Models of seismic instruments. Seismological Research Letters, 81(6): 972-983. doi: 10.1785/gssrl.81.6.972

Swensen, E. A., Barron, A. A., Farrar, C. R. et al., (1997). Randon vibration sensitivity studies of modeling uncertainties in the NIF structures. In Proceedings of the 15th International Modal Analysis Conference (IMAC XV): 1172-1180. Orlando, FL, USA

White, D. C. (2005). Orion building vibration monitoring. Consultancy Report. 1-54. DC White \& Partners, Hants, UK. 


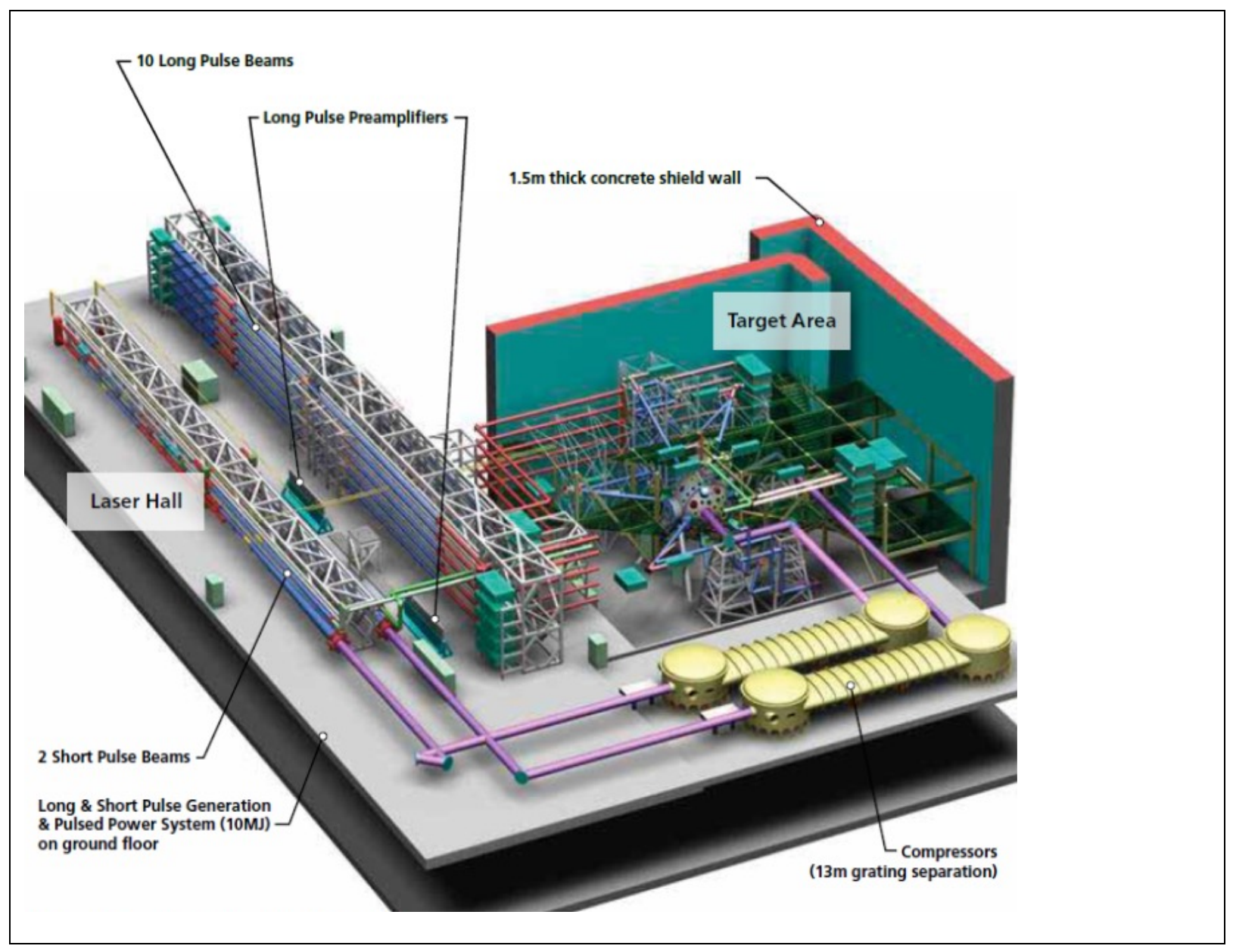

Figure 1: Orion schematic. 


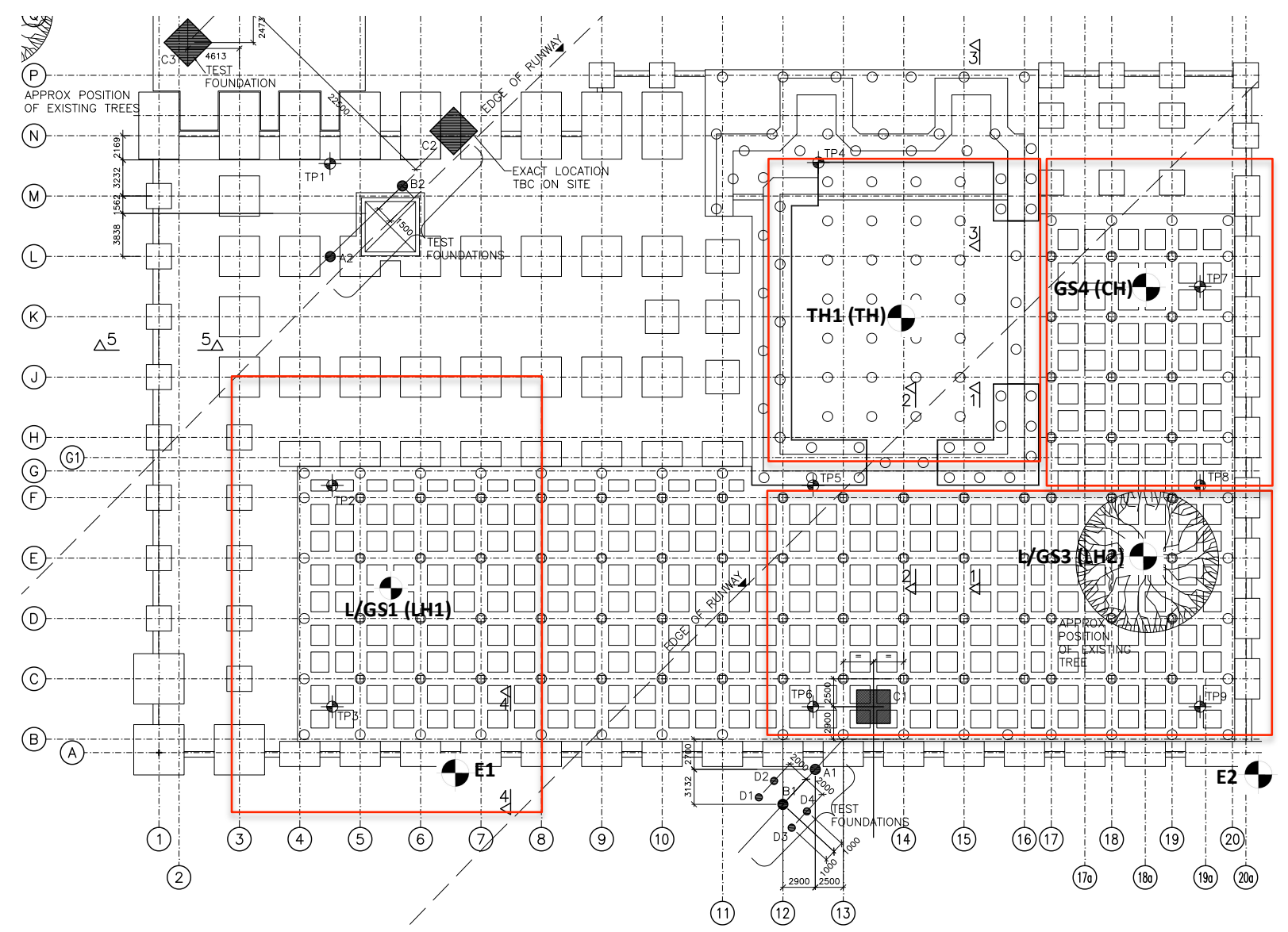

Figure 2: Orion site 

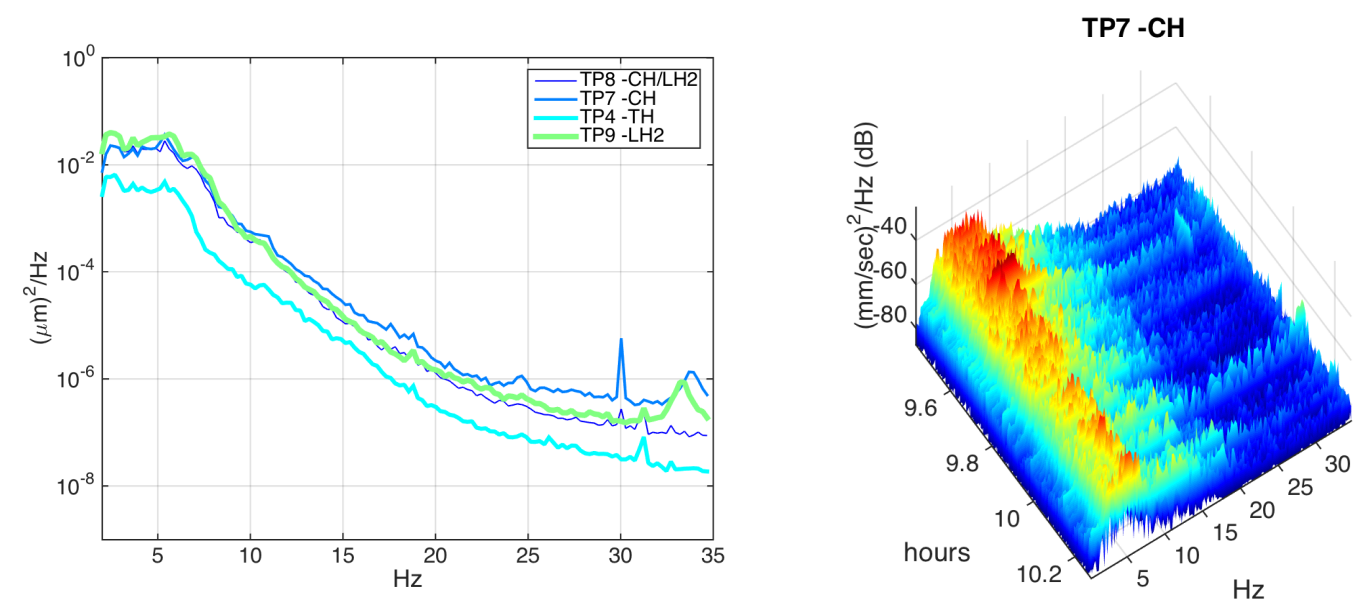

Figure 3: Vibration environment on $22^{\text {nd }}$ September 2005 for brownfield site. Left: $95 \%$ ile PSD, right velocity spectrogram (reference $1 \mathrm{~mm} / \mathrm{sec}$ )
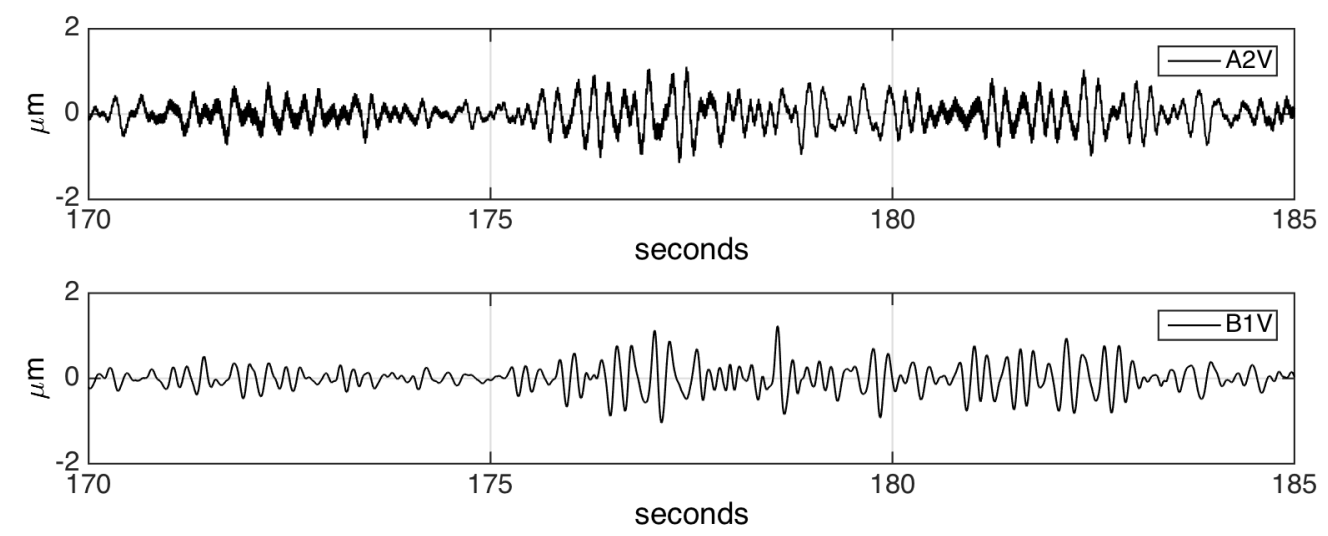

Figure 4: Signal_02 original time series 


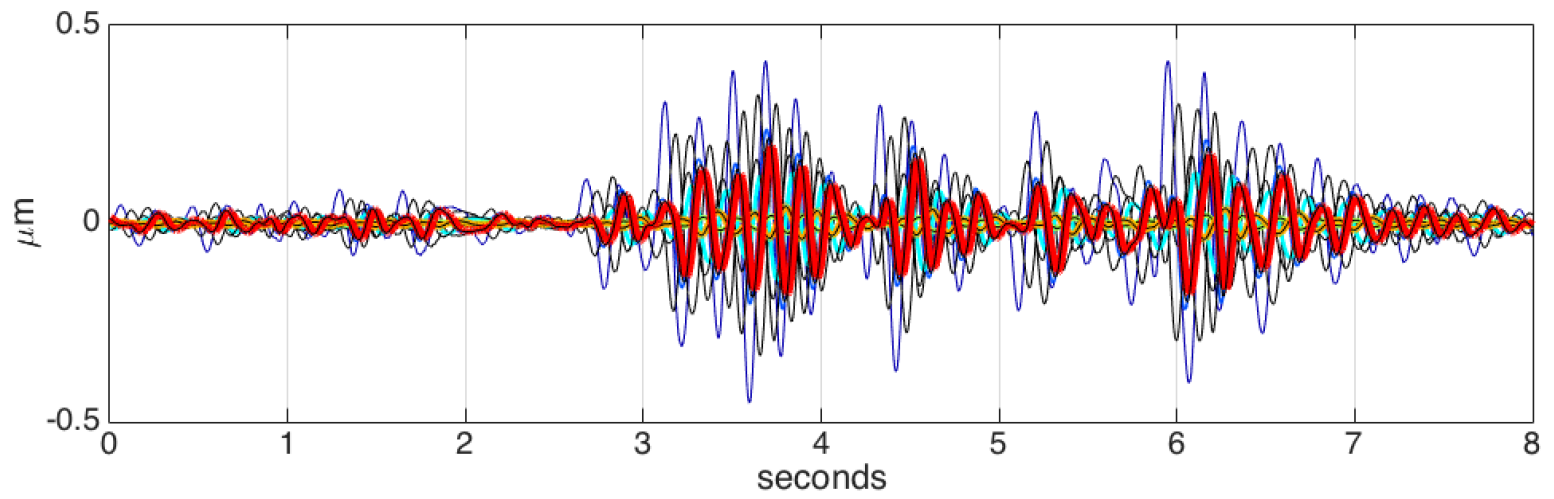

Figure 5: Set of generated input signals. 

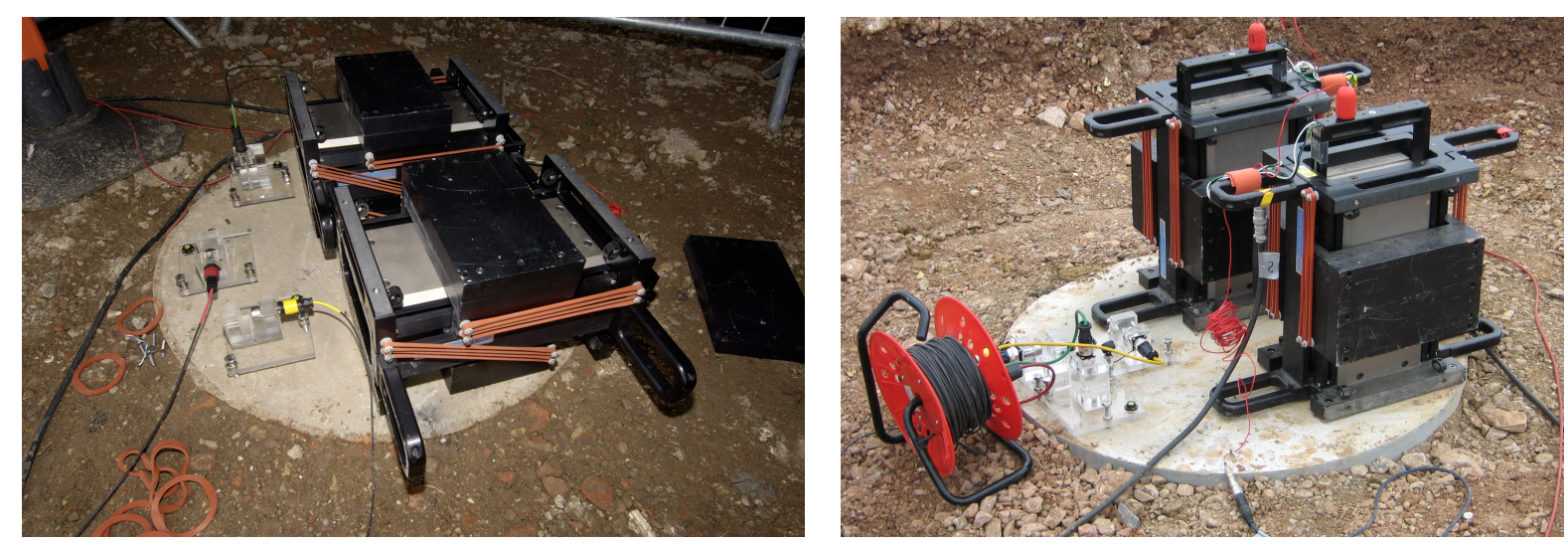

Figure 6: Shaker pile tests 

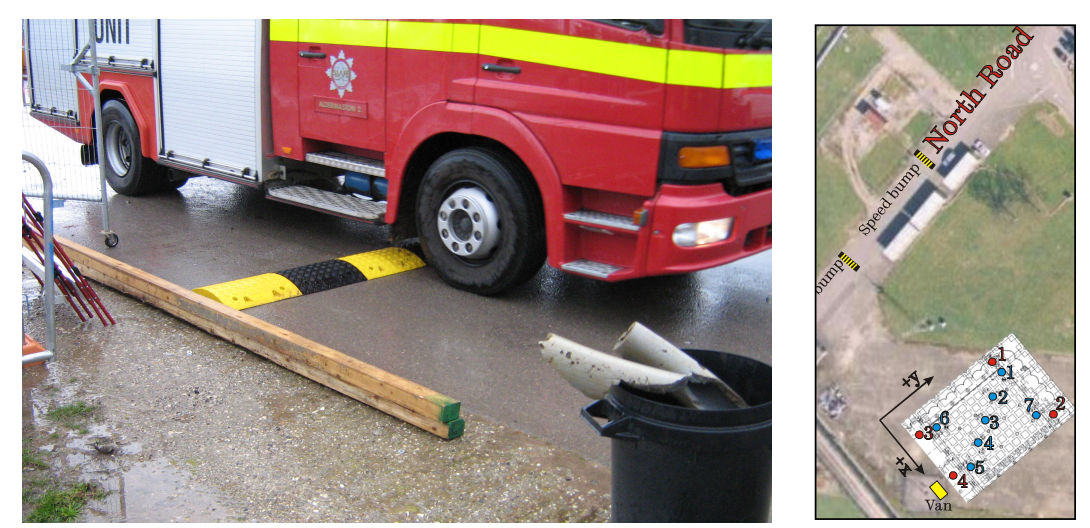

Figure 7: Fire engine and 'fire bump' location 

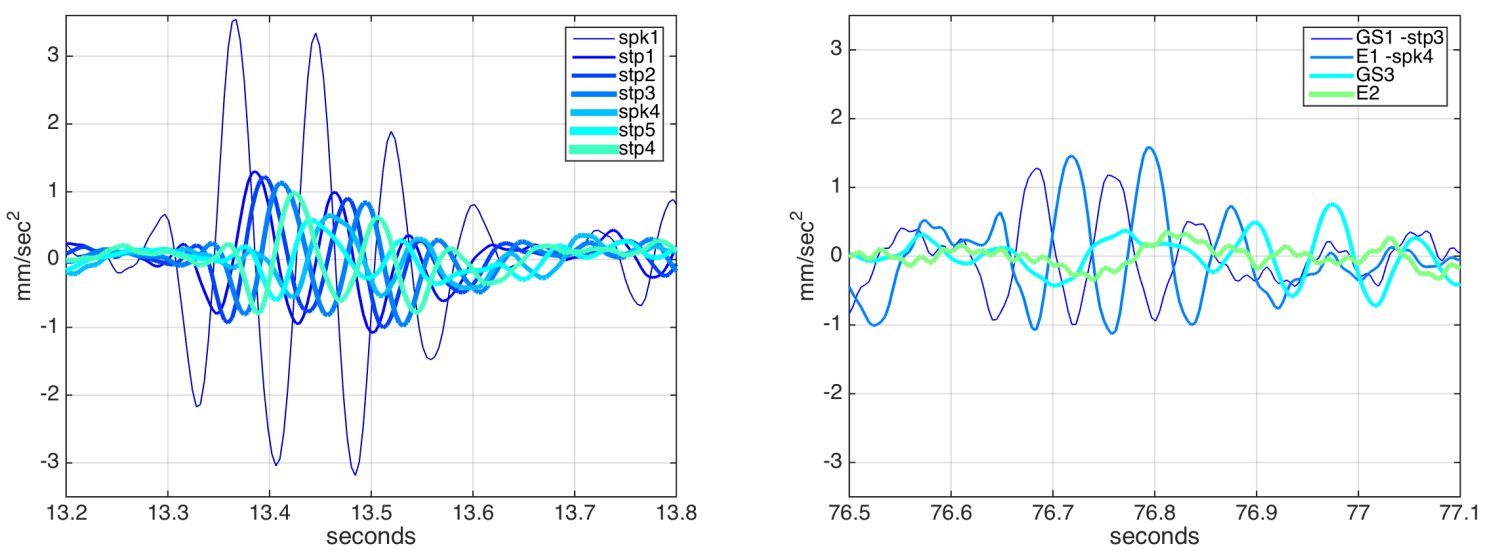

Figure 8: Fire bump time histories. Left for 2006 slab-only measurements and right for 2007 slab+partial structure measurements. 

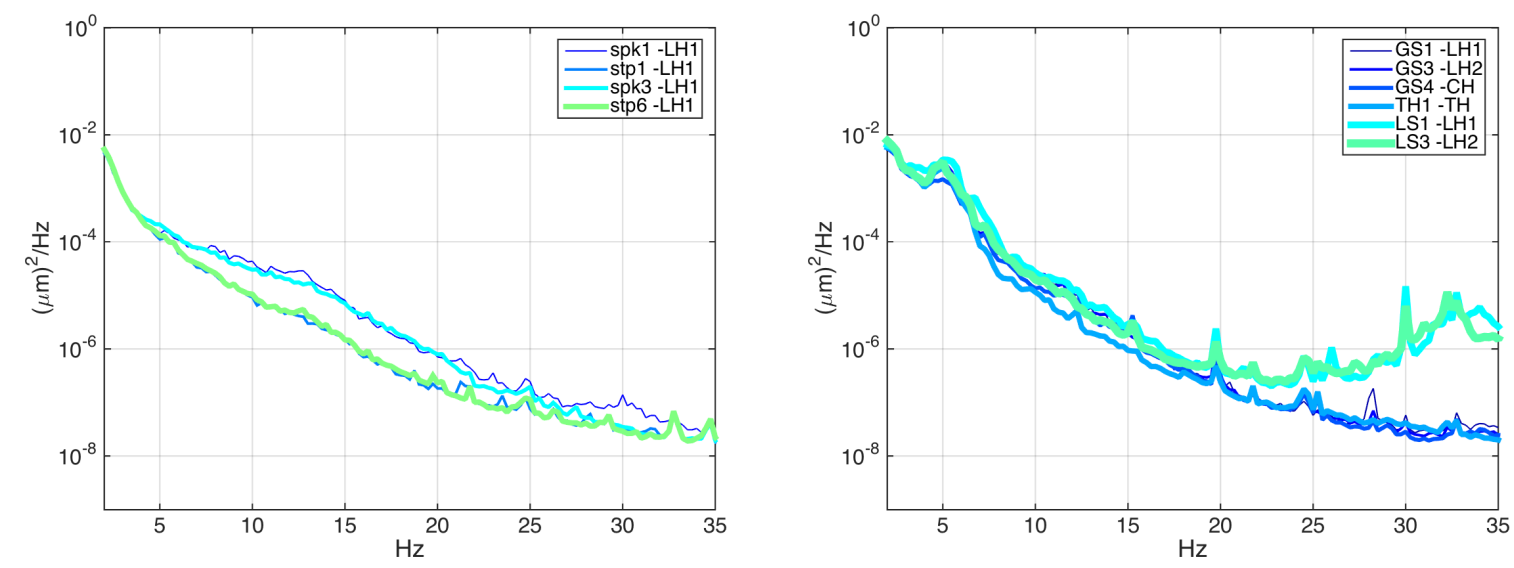

Figure 9: PSDs of vertical vibration with construction of 2006 and 2007 measurements. stp3 (2006) compares with GS1 (ground floor slab) and LS1 (first floor slab) in 2007. 

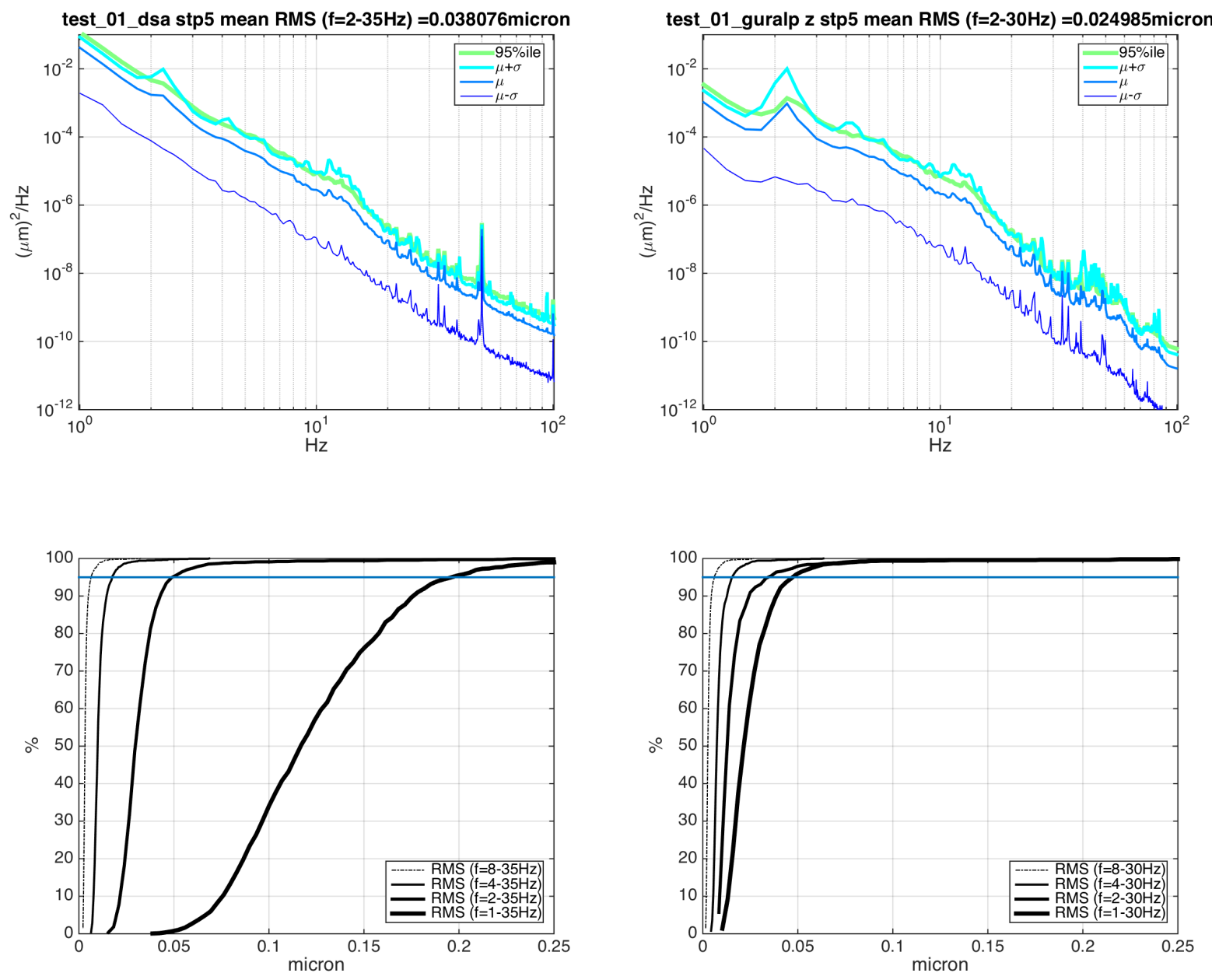

Figure 10: Comparison of Ground floor slab response using FBA and Guralp CMG-3ESP. 

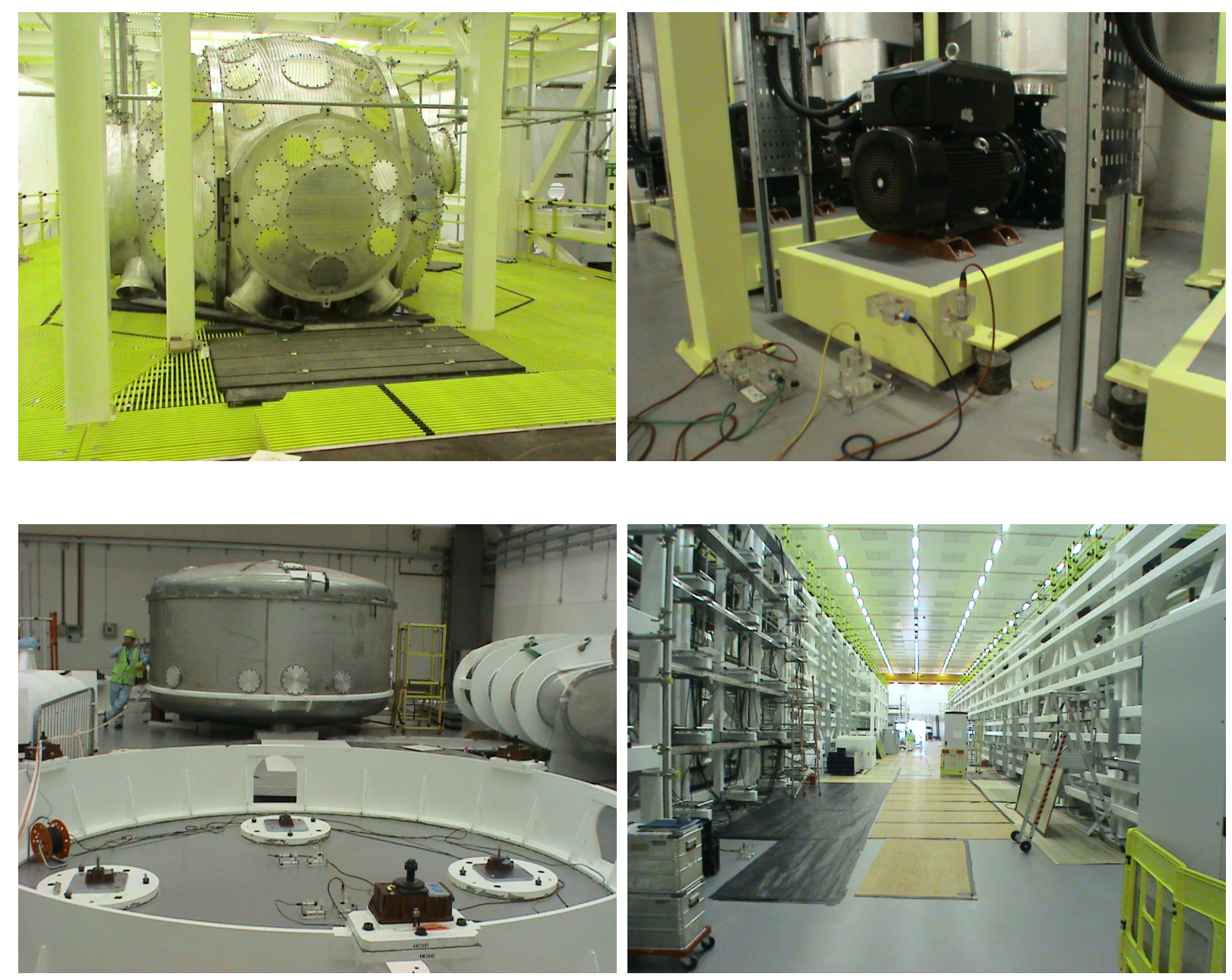

Figure 11: Optical and mechanical machinery. From top left, clockwise: target chamber, chilled water pump in plant room, short/long pulse laser frames, optical compressor. 


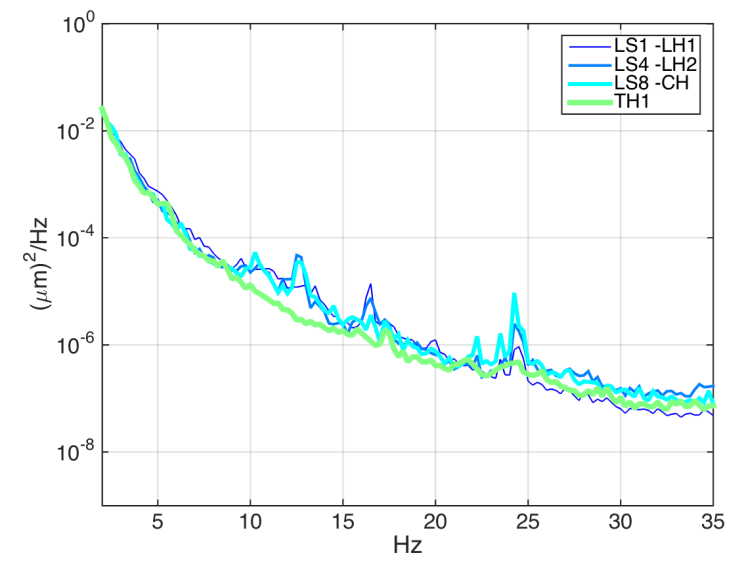

Figure 12: Displacement PSDs in laser hall and target hall from 2009 measurements. 


\section{References}

Al Dimashki, M. M. (2011). Effects of ground vibrations on the performance of foundation structures. University of Sheffield.

Brownjohn, J. M. W. (2007). Noise characteristics of sensors for extreme low level vibration measurements. In Proceedings of the 25th International Modal Analysis Conference (IMAC $X X V)$ (pp. 1-8). Orlando, FL, USA. Retrieved from http://vibration.ex.ac.uk/doc/P00393.pdf

Dobry, R., \& Gazetas, G. (1988). Simple method for dynamic stiffness and damping of floating pile groups. Géotechnique, 38(4), 557-574. doi:10.1680/geot.1988.38.4.557

Edwards, C. (2006). Project Orion : Journey to the hottest most dense place on earth. Defence Management Journal, (34), 86-88.

Hao, H., Oliveira, C. S., \& Penzien, J. (1989). Multiple-station ground motion processing and simulation based on smart-1 array data. Nuclear Engineering and Design, 111(3), 293-310. doi:10.1016/0029-5493(89)90241-0

Hoarty, D. J., Allan, P., James, S. F., Brown, C. R. D., Hobbs, L. M. R., Hill, M. P., ... Emig, J. (2013). The first data from the Orion laser; measurements of the spectrum of hot, dense aluminium. High Energy Density Physics, 9(4), 661-671. doi:10.1016/j.hedp.2013.06.005

Oades, K., Evans, A., Slark, G., Foster, J., Eagleton, R., \& Clark, E. (2004). Target diagnostics for the future AWE Orion laser facility. Review of Scientific Instruments, 75(10), 4222. doi:10.1063/1.1787605

Randall, R. B. (1987). Frequency analysis (p. -). Naerum, Denmark: Bruel \& Kjaer.

Ringler, A. T., \& Hutt, C. R. (2010). self-noise Models of seismic instruments. Seismological Research Letters, 81(6), 972-983. doi:doi: 10.1785/gssrl.81.6.972

Swensen, E. A., Barron, A. A., Farrar, C. R., Cornwell, P., Alamos, L., Student, P. D., \& Eng, C. (1997). Randon vibration sensitivity studies of modeling uncertainties in the NIF structuresMS P946. In Proceedings of SPIE, the International Society for Optical Engineering (pp. 1172 1180). SPIE.

White, D. C. (2005). Orion building vibration monitoring (pp. 1-54). 